\title{
An Improved Differential Strain Analysis Method for Super Deep Wells
}

\author{
L.H. Pan*, S.C. Zhang and J. Zhang \\ School of Petroleum Engineering, China University of Petroleum, Beijing, 102200, China
}

\begin{abstract}
The deeper a reservoir is, the smaller diameter the drilled full diameter cores have. It is difficult to conduct insitu stress experiments with conventional methods if the diameter of the full diameter cores is less than $6.0 \mathrm{~cm}$, especially for cores abundant in natural fractures. In this paper, based on conventional Differential Strain Analysis (DSA) methods and wave velocity anisotropy methods, we developed an improved Differential Strain Analysis (DSA) method that is specially designed for small full diameter cores. The improved method, combined with the paleomagnetic core reorientation tests, can predict magnitude and orientation of in-situ stress. Results from the improved method are very close to those obtained from conventional Differential Strain Analysis. The improved method was applied to carbonate cores in Tahe Oilfield, which has a depth up to 6000 meters and has cores with a diameter from $5.5 \mathrm{~cm}$ to $6.0 \mathrm{~cm}$. The experimental results with the improved method show good consistence with the field-monitored ones, which shows that the improved method is reliable and practical.
\end{abstract}

Keywords: In-situ stress, laboratory test, wave velocity anisotropy, improved DSA method, super deep reservoir.

\section{INTRODUCTION}

Many in-situ stress testing technologies have been developed with the development of rock mechanics [1], but strictly speaking, there is not a direct testing method. Laboratory experiment is the main approach to predicate orientation and magnitude of in-situ stress. As known to all, the testing samples are cores in the laboratory, so cores' size and physical properties are important to the laboratory experiments.

For non-directional cores, it is necessary to conduct paleomagnetic core reorientation experiment [2], but the final results should be confirmed by integrating with wave velocity anisotropy experiments, differential strain analysis experiments or kaiser effect of acoustic emission experiments.

There are two main laboratory experiments on magnitude of in-situ principal stress, as follows:

(1) Kaiser effect of acoustic emission test. Acoustic emissions (AE) are transient elastic waves created by sudden changes of inner stress state in the solid under a mechanical load $[3,4]$. It is important to determine the Kaiser point accurately, but for many cores, the Kaiser point may be ambiguous and is hard to determine with AE tests. At present, there is no effective method [5] for this challenge. Cores may be subject to multiple geologic processes after rock formation generation. There are different views on whether cores memorize the in-situ maximum stress only at geologic period or in-situ stress at different periods.

\footnotetext{
*Address correspondence to this author at the School of Petroleum Engineering, China University of Petroleum, Beijing, 102200, China;

Tel: 010-89734593; Fax: 010-89734593;

E-mail:plh_cup@163.com
}

(2) Conventional Differential Strain Analysis (DSA) method. The magnitude and the orientation of in-situ principal stress can be predicated by Differential Strain Analysis experiments. The theory of Differential Strain Analysis (DSA) is rigorous and already proven [6,7], but more than six foil strain gages are needed in experiments, and all gages must have conformability. Due to the experimental difficulty, high workload, and low experimental efficiency, conventional Differential Strain Analysis (DSA) experiment has been restricted in application at times [8].

The main objective of this study is to introduce an improved Differential Strain Analysis (DSA) for deep or super deep wells. This method is designed for cylindrical cores whose diameter is between $5.0 \mathrm{~cm}$ and $7.0 \mathrm{~cm}$, and height is $6.0 \mathrm{~cm}$. Combined with paleomagnetic core reorientation method and wave velocity anisotropy method, the improved method can predict the orientation and magnitude of in-situ principal stress. We compared the results predicted by the improved Differential Strain Analysis (DSA) with the ones predicted by the conventional Differential Strain Analysis (DSA) and compared the experimental results from the improved method and field monitored results. The comparison shows that the improved Differential Strain Analysis (DSA) method is reliable and practical.

\section{EXPERIMENTAL PROGRAM}

\subsection{Experimental Philosophy}

The full diameter cores that were drilled from deep or super deep reservoir have small diameter between $5.0 \mathrm{~cm}$ to $6.0 \mathrm{~cm}$, while the diameter of general full diameter cores is between $9.5 \mathrm{~cm}$ to $11.0 \mathrm{~cm}$. If Kaiser effect of acoustic emission test is used, at least 4 standard cores (diameter is $2.5 \mathrm{~cm}$, length is $5.0 \mathrm{~cm}$ ) must be drilled from the same full 
diameter core, which requires the length of full diameter core longer than $15.0 \mathrm{~cm}$. For an elastic strain recovery (3D-ASR), the core diameter should be more than $7.5 \mathrm{~cm}$, but the full diameter cores drilled from deep or super deep reservoirs are too small to meet the requirement. In conventional Differential Strain Analysis (DSA) experiments, samples need to be cut into cubes with length about $6.0 \mathrm{~cm}$ on each direction. Full diameter cores from deep or super deep reservoirs cannot be cut into a cube used in Differential Strain Analysis (DSA) experiments. Therefore, a new approach needs to be designed to measure the magnitude of in-situ stress with cores from deep or super deep reservoirs.

Based on the available apparatuses and general differential strain analysis method [9], we developed an improved differential strain analysis method. The improved DSA aims at cylindrical cores with the diameter from $5.0 \mathrm{~cm}$ to $7.0 \mathrm{~cm}$, and in the paper the diameter of the experimental cores is from $5.5 \mathrm{~cm}$ to $6.0 \mathrm{~cm}$.

Magnitude of in-situ principal stress is predicted with cylindrical cores by improved Differential Strain Analysis (DSA) experiments and wave velocity anisotropy experiments. Because the experimental cores is nondirectional, paleomagnetic core reorientation experiments must be conducted for the orientation of in-situ horizontal principal stress.

The details about the distinction between improved Differential Strain Analysis (DSA) method and the conventional Differential Strain Analysis (DSA) method are as follows.

(1) Different shape of test samples. Hexahedral samples approximately $6.0 \mathrm{~cm}$ on each side were used in conventional Differential Strain Analysis (DSA) method. While in deep or super-deep reservoirs, the diameter of full diameter cores is less than $6.0 \mathrm{~cm}$, so that hexahedral samples cannot be cut with the obtained cores. Cylindrical samples with a diameter of $5.5 \mathrm{~cm}$ and a height of $6.0 \mathrm{~cm}$ were used in the improved method.

(2) Different cells that measure strain in experiments. Electric wire strain gauges were used in conventional Differential Strain Analysis (DSA), and nine strain foils were fixed on three surfaces of cube with a glue. In convention methods experimental error is large with strain foils, and strain foils can't be pasted up on the lateral face of the cylinder, so high precision transmitters were applied to measure the strain in this paper. The transmitter of Differential Strain Analysis (DSA) looks like the one in tri-axial stress experiments, but its measurement precision and sensitivity are higher than the one used in tri-axial stress experiments.

\subsection{Experimental Process}

The experimental process in this paper is as follows:

(1) Sample preparation. Cylindrical test samples with a diameter of $5.5 \mathrm{~cm}$ and a height of $6.0 \mathrm{~cm}$ were cut from full diameter cores. The cylindrical test samples must be homogeneous and have no natural fracture because natural fractures have a significant impact on the precision of experimental results.
(2) Wave velocity anisotropy experiments. Making use of supersonic wave (a type of P-wave), measure wave propagation velocities in the rock along with circular face of cylindrical test sample. According to the maximum and minimum velocities, orientation of in-situ horizontal principal stress of cores is determined. Then orientation lines of in-situ maximum horizontal stress are marked on the lateral face and end face.

(3) Improved Differential Strain Analysis experiments. Firstly, all faces of cores are filmed with epoxy in order to prevent the pressure liquid from seeping into cores. Secondly, according to orientation lines of in-situ maximum horizontal stress, the high precision transmitters are assembled along the orientation of the maximum and the minimum in-situ stress on the lateral face and the vertical direction, as shown in Fig. (1). Thirdly, put cores into the pressure cabin and pressurize at the same time, and then we record the strain at different pressures. Experimental apparatus in the improved Differential Strain Analysis experiments is Geotechnical Consulting and Testing System.

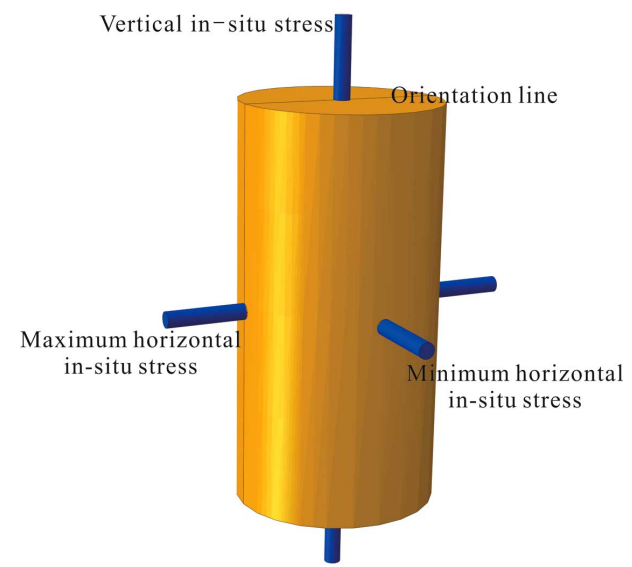

Fig. (1). Sketch map of installing transmitters.

(4) Paleomagnetic core reorientation experiments. The test samples used in DSA method can be re-used in paleomagnetic core reorientation experiments by drilling core with $2.5 \mathrm{~cm}$ diameter and $2.0 \mathrm{~cm}$ height from the test samples used in DSA method. All drilled cores must be marked a sign line of in-situ maximum horizontal principal stress at the end of face. Paleomagnetic core reorientation methods, combined with the wave velocity anisotropy experiments, were implemented to obtain the orientation of in-situ maximum horizontal principal stress in reservoirs.

\subsection{Verification of the Improved Method}

In order to verify the accuracy of improved Differential Strain Analysis (DSA) method proposed in this paper, four full diameter cores from the same well and same depth were cut into two kinds of shapes. Two cores cut into hexahedron about $6.0 \mathrm{~cm}$ on each side, as shown in the left of Fig. (2), were tested with conventional Differential Strain Analysis (DSA) method. Other two cores cut into cylinder with a diameter of $5.5 \mathrm{~cm}$ and a height of $6.0 \mathrm{~cm}$, as shown in the right of Fig. (2), were tested with the improved Differential Strain Analysis (DSA). 


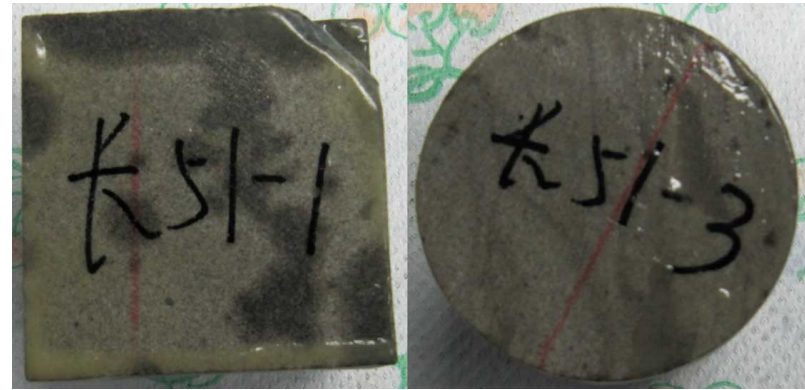

Fig. (2). Test core samples for the conventional method and the improved method.

Results from the two methods are shown in Table 1. For the conventional method, mean of in-situ maximum horizontal principal stress is $42.96 \mathrm{MPa}$, and mean of in-situ minimum horizontal principal stress is $26.04 \mathrm{MPa}$; for the improved method, mean of in-situ maximum horizontal principal stress is $44.17 \mathrm{MPa}$, and mean of in-situ minimum horizontal principal stress is $27.75 \mathrm{MPa}$. The two methods give values close each other. In addition, the two cores measured with the improved method give closer value compared the two cores measured with the conventional method. The comparison shows that the method is reliable.

\section{EXPERIMENTAL RESULTS}

According to experimental program proposed in this paper, nine full diameter cores from Tahe Oilfield were experimented for the orientation and magnitude of in-situ stress, and the experiment results are shown as follows.

\subsection{Orientation of In-Situ Horizontal Principal Stress}

As full diameter cores were pulled out of the wells, stress state of the cores changed from initial conditions. Lots of micro-cracks were generated and would be filled with air when the stress is released. Development level of microcracks is dependent on the magnitude and orientation of insitu principal stress. Since wave propagation velocity is different at the directions of the maximum and minimum insitu horizontal stress, velocity in the direction of in-situ maximum horizontal principal stress is the slowest, while velocity in the direction of in-situ minimum horizontal principal stress is the fastest. According to this principle, the

Table 1. Results of two Differential Strain Analysis (DSA) Experimental Methods

\begin{tabular}{|c|c|c|c|c|c|}
\hline \multirow{2}{*}{ Cores No. } & \multirow{2}{*}{ Depth(m) } & \multicolumn{2}{|c|}{ Three-Dimensional in-Situ Stress (MPa) } & \multirow{2}{*}{$\begin{array}{c}\text { Experimental Method } \\
\text { Minimum }\end{array}$} \\
\cline { 3 - 5 } & Vertical & $\begin{array}{c}\text { Horizontal } \\
\text { Maximum }\end{array}$ & 25.97 & Conventional DSA \\
\hline \hline Chang51-1 & $1517.43-1517.58$ & 36.43 & 42.89 & 26.10 & Conventional DSA \\
\hline Chang51-2 & $1517.43-1517.58$ & 36.43 & 43.03 & 27.82 & Improved DSA \\
\hline Chang51-3 & $1517.43-1517.58$ & 36.43 & 43.86 & 27.68 & Improved DSA \\
\hline Chang51-4 & $1517.43-1517.58$ & 36.43 & 44.48 & 2 & 2 \\
\hline
\end{tabular}

Table 2. The Results of Rock Wave Velocity along Circumferential Direction on TPX1

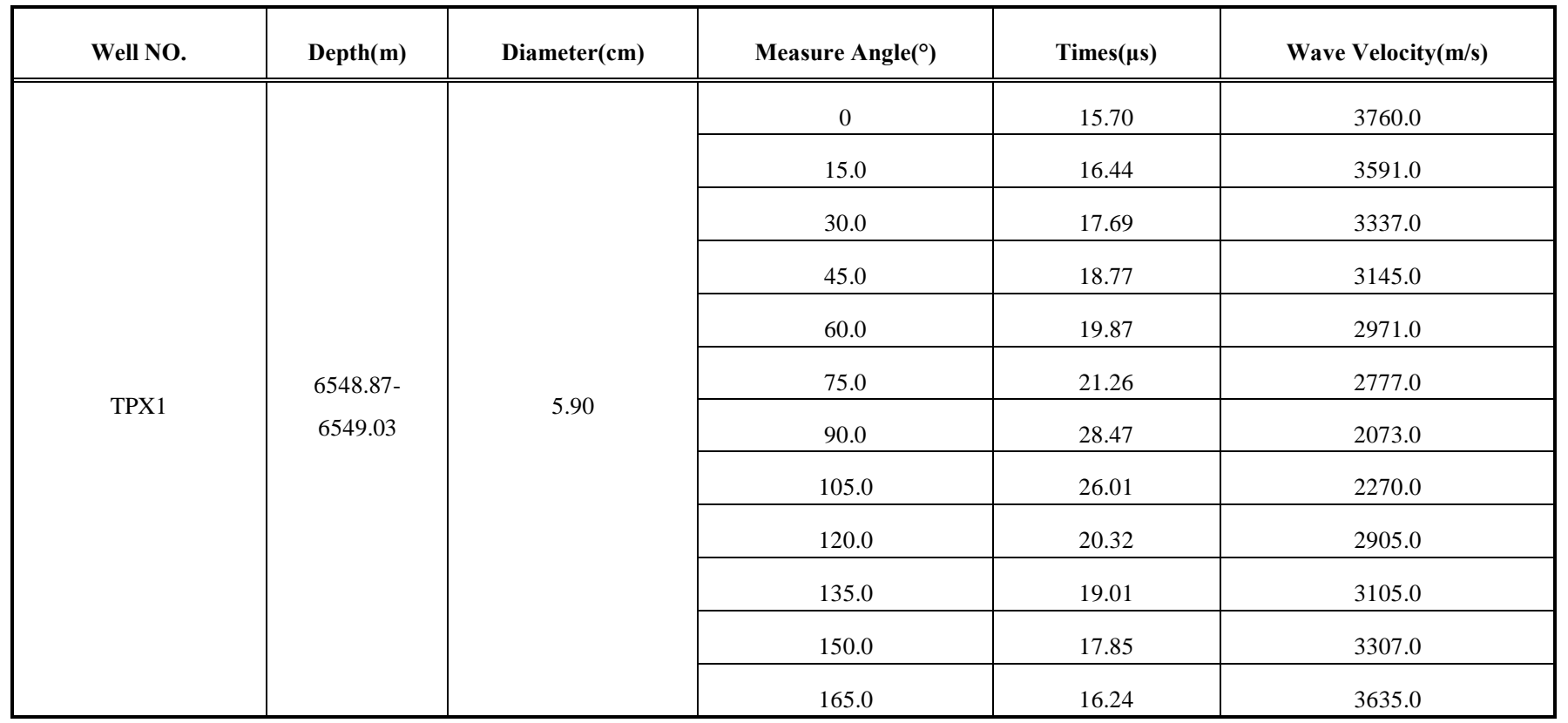


direction of in-situ horizontal principal stress can be obtained by wave velocity anisotropy experiments.

With the supersonic wave technology, radial propagation velocities along the circumferential direction can be obtained. Table $\mathbf{2}$ is the propagation velocity results of a full diameter core from TPX1 well. A sine or cosine curve can be fitted in the plot of propagation velocity versus degree of angle. The fitted curve of TPX1 well is shown in Fig. (3a). The propagation velocity at $0^{\circ}$ is the fastest, so $0^{\circ}$ is the orientation of in-situ minimum horizontal principal stress for this core. The propagation velocity at $90^{\circ}$ is the slowest, so $90^{\circ}$ is the orientation of in-situ maximum horizontal principal stress. All fitted curves of TPX1 well to TPX6 well are shown in Fig. (3). The direction of in-situ maximum horizontal principal stress can be calculated by the results of wave velocity anisotropy experiments.

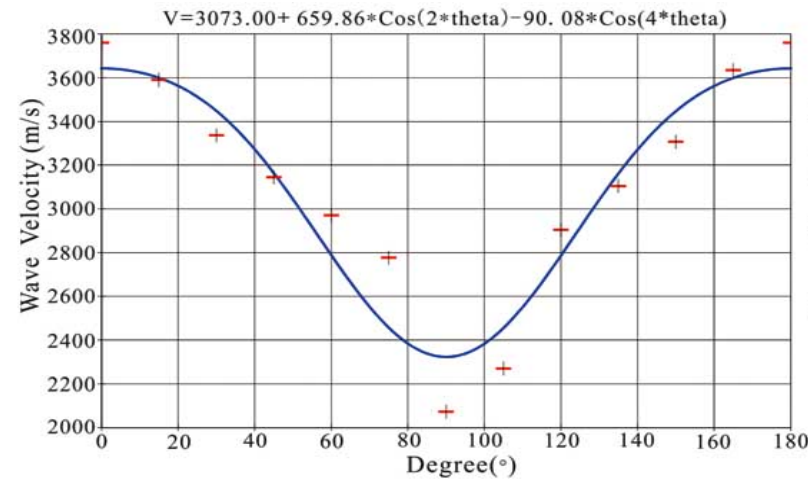

a. TPX1 well

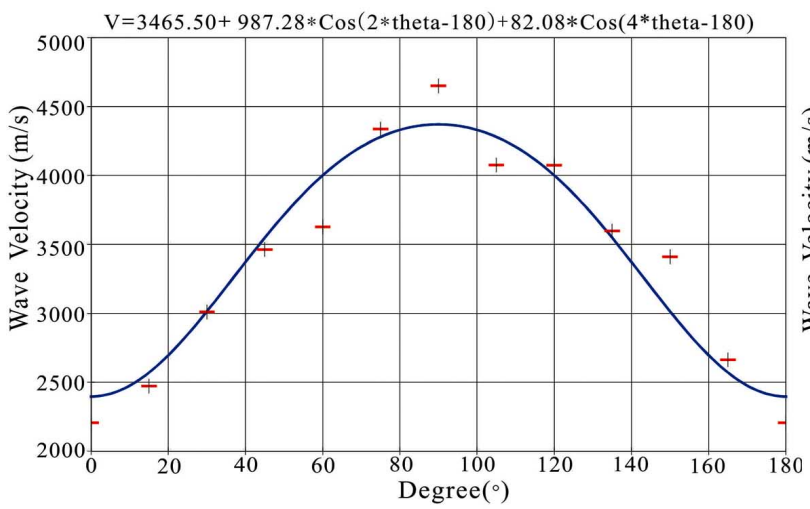

c. TPX3 well

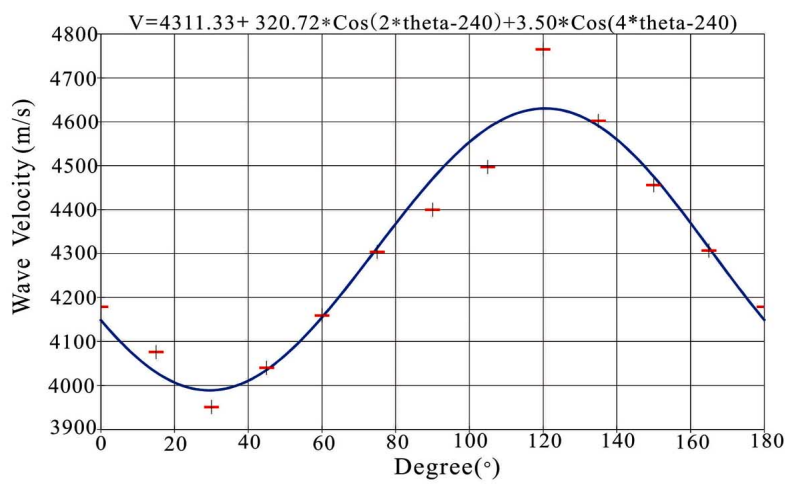

e. TPX5 well
For non-orientated cores, only relative orientation can be obtained with the rock wave velocity anisotropy experiments. In order to get the actual in-situ principal stress orientation, paleomagnetic core reorientation tests are necessary. From the paleomagnetic core reorientation tests, the angle between north geographic pole and the sign line of in-situ maximum horizontal stress, and geomagnetic inclination can be obtained according to the results of viscous remnant magnetization (VRM). Table $\mathbf{3}$ is the results of paleomagnetic experiments with the samples from TPX1 well. According to the angle between north geographic pole and the sign line of in-situ maximum horizontal stress and geomagnetic inclination, the initial direction of full diameter cores can be determined by the statistical results (Fisher statistical method). The Fisher statistical projection drawing of samples from TPX1 well is shown in Fig. (4a), which

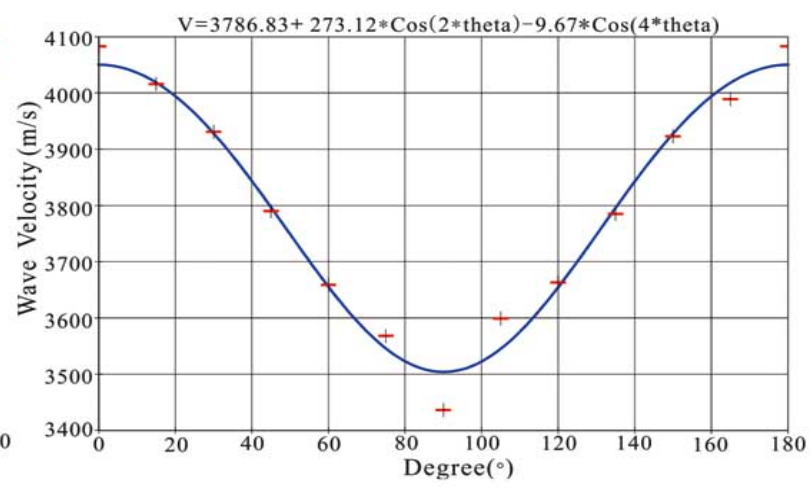

b. TPX2 well

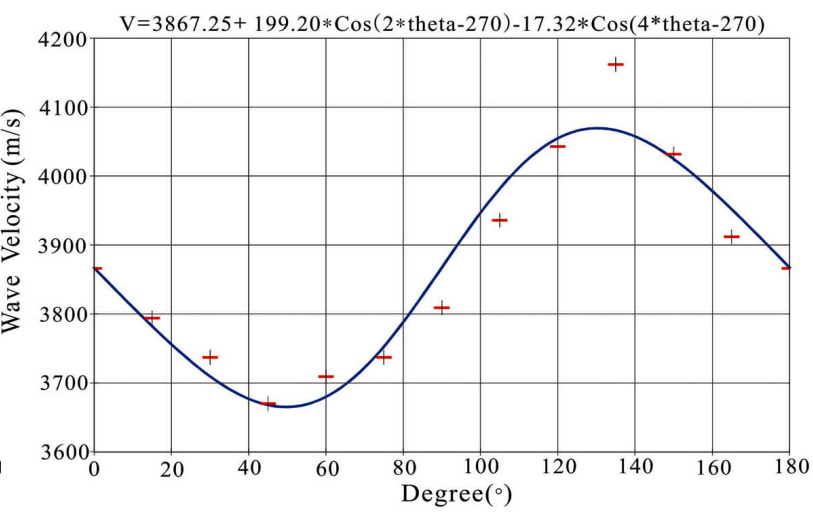

d. TPX4 well

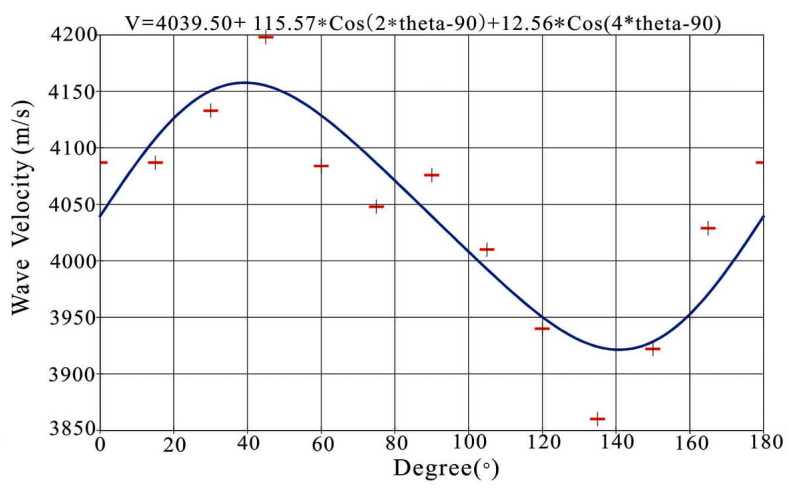

f. TPX6 well

Fig. (3). Fitted curves of rock wave velocity versus degree of angle for samples from TPX1 well to TPX6 well. 
Table 3. Results of Paleomagnetic Core Reorientation of Cores from TPX1 Well

\begin{tabular}{|c|c|c|c|c|c|c|}
\hline Well No. & $\operatorname{Depth}(m)$ & Cores No. & Data Range & Angle $\left(^{\circ}\right)$ & $\begin{array}{l}\text { Geomagnetic } \\
\text { Inclination }\left({ }^{\circ}\right)\end{array}$ & $\begin{array}{l}\text { Confidence } \\
\text { Degree }\left(\alpha_{95}\right)\end{array}$ \\
\hline \multirow{7}{*}{ TPX1 } & \multirow{7}{*}{$\begin{array}{l}6548.87- \\
6549.03\end{array}$} & $\mathrm{H} 1$ & $\mathrm{~T} 100-\mathrm{T} 260$ & 85.5 & 69.8 & $3.0 \%$ \\
\hline & & $\mathrm{H} 3$ & NRM-T260 & 66.3 & 69.2 & $4.7 \%$ \\
\hline & & $\mathrm{H} 4$ & NRM-T300 & 112.7 & 71.3 & $5.5 \%$ \\
\hline & & H5 & NRM-T300 & 90.0 & 64.4 & $3.6 \%$ \\
\hline & & H6 & T100-T300 & 94.6 & 61.3 & $4.2 \%$ \\
\hline & & $\mathrm{H} 7$ & NRM-T300 & 97.5 & 63.2 & $2.5 \%$ \\
\hline & & \multicolumn{2}{|c|}{ Statistical result } & 91.7 & 67.1 & $3.9 \%$ \\
\hline
\end{tabular}
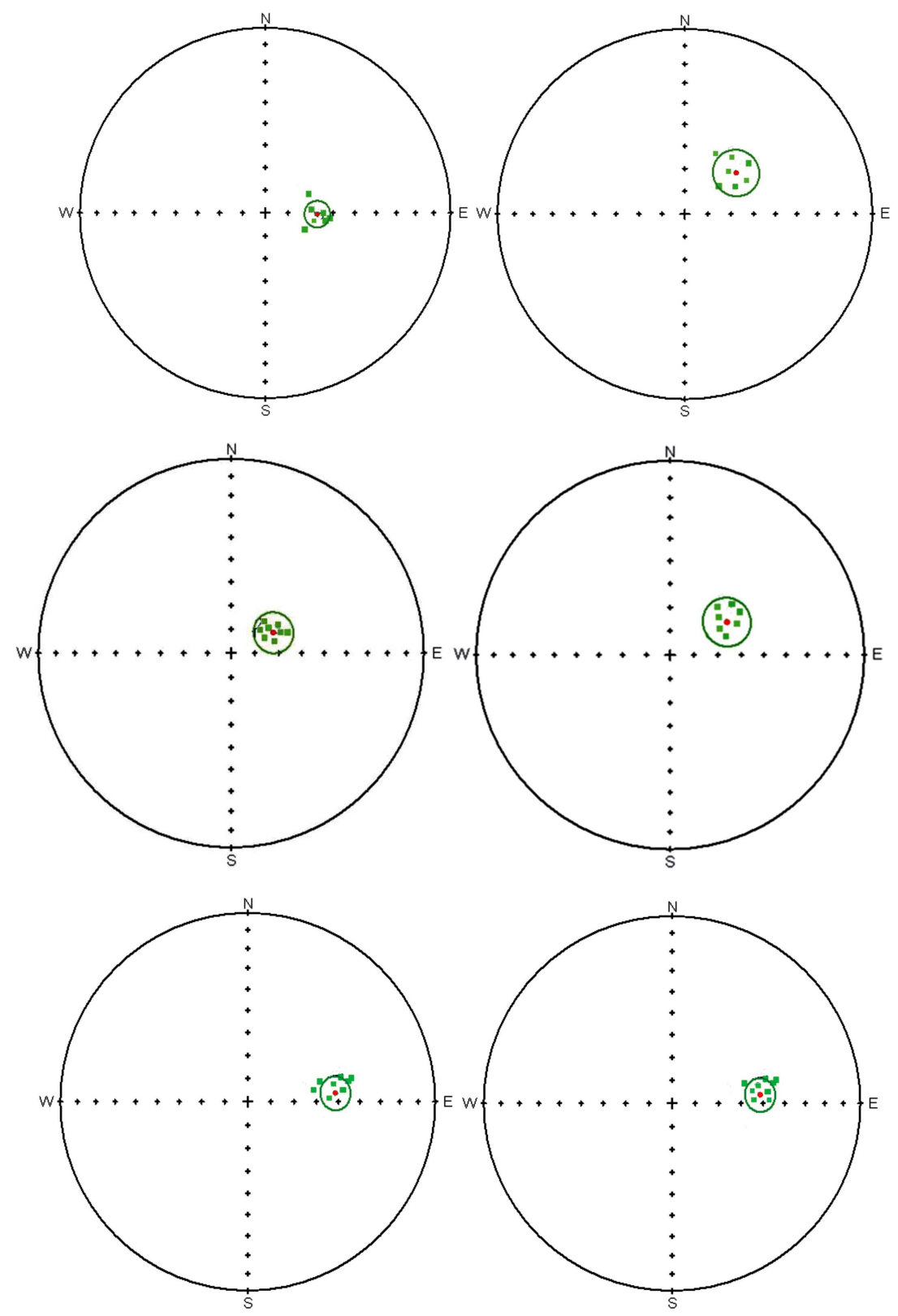

Fig. (4). Statistical results (Fisher statistical method) of viscous remnant magnetization (VRM) of the samples from TPX1 well to TPX6 well.

shows that the angle $91.7^{\circ}$. The Fisher statistical projection drawings of TPX1 well to TPX6 well are shown in Fig. (4), and the direction of in-situ maximum horizontal stress is shown in Table $\mathbf{4}$ accordingly. 
Once the initial direction of full diameter cores before drilling in actual reservoirs was obtained, the actual orientation of in-situ horizontal principal stress can be determined with two experiments together.

After paleomagnetic core reorientation tests and wave velocity anisotropy tests for rock distribution characteristics were done, the orientation of in-situ maximum horizontal principal stress in Tahe Oilfield is found among NE $45^{\circ}$ and NE $94^{\circ}$. The details are shown in Table 4.

Table 4. Results of In-situ Stress Orientation of the Carbonate Reservoir in Tahe Oilfield

\begin{tabular}{|c|c|c|}
\hline Well NO. & Depth of Cores(m) & $\theta\left(\mathbf{N E},{ }^{\circ}\right)$ \\
\hline \hline TPX1 & $6548.87-6549.03$ & 91.7 \\
\hline TPX2 & $6492.09-6492.2$ & 50.6 \\
\hline TPX3 & $6844.39-6844.54$ & 65.4 \\
\hline TPX4 & $6362.99-6363.14$ & 60.5 \\
\hline TPX5 & $6158.44-6158.55$ & 81.1 \\
\hline TPX6 & $6274.38-6275.53$ & 78.2 \\
\hline TPX7 & $6828.73-6828.9$ & 80.1 \\
\hline TPX8 & $7005.99-7006.22$ & 72.2 \\
\hline TPX9 & $6211.21-6211.42$ & 65.0 \\
\hline
\end{tabular}

\subsection{Magnitude of In-situ Principal Stress}

When cores were drilled from reservoir, the degree of unloading is different in different directions because threedimensional principal in-situ stresses are different from each other. The micro-fracture strain relative to degree of unloading are formed when in-situ stress is released. When a constant confining pressure is preloaded, strain recovery is different in the three directions of three principal in-situ stress, so the direction of maximum strain represents the orientation of in-situ maximum stress before the core was drilled from the reservoir.

Three strain curves of principal in-situ stress were obtained by improved Differential Strain Analysis (DSA) tests in the paper. Some strain curves of TPX1 well to TPX6 well are shown in Fig. (5). Vertical in-situ stress was calculated from density logging according to equation (1). The maximum and minimum of horizontal in-situ stress of the carbonate reservoir in Tahe Oilfield are shown in Table 5.

$$
\begin{aligned}
\sigma_{v}: \sigma_{H}: \sigma_{h}= & {\left[\mu\left(\varepsilon_{H}+\varepsilon_{h}\right)+(1-\mu) \varepsilon_{v}\right] } \\
& :\left[\mu\left(\varepsilon_{v}+\varepsilon_{h}\right)+(1-\mu) \varepsilon_{H}\right] \\
& :\left[\mu\left(\varepsilon_{v}+\varepsilon_{H}\right)+(1-\mu) \varepsilon_{h}\right]
\end{aligned}
$$

\section{COMPARISON BETWEEN EXPERIMENTAL RE- SULTS AND FIELD MONITORED RESULTS}

\subsection{Comparison of Orientation}

The orientation of the acid fracture in Tahe Oilfield was monitored by micro-seismic. Accordingly, the orientation of in-situ maximum horizontal principal stress can be obtained from the monitoring results. Due to natural fractures and faults, monitored orientation is distributed in a wide range, with $71 \%$ among $\mathrm{NE} 45^{\circ}$ and $\mathrm{NE} 90^{\circ}$. The monitored results show that there are 15 wells with the acid fracture orientation among $\mathrm{NE} 0^{\circ}$ and $\mathrm{NE} 45^{\circ}, 70$ wells with the orientation among $\mathrm{NE} 45^{\circ}$ and $\mathrm{NE} 90^{\circ}$, and 13 wells with the orientation among $\mathrm{NE} 90^{\circ}$ and $\mathrm{NE} 180^{\circ}$. Most monitored orientations are distributed among $\mathrm{NE} 45^{\circ}$ and $\mathrm{NE} 90^{\circ}$. Most results from experiments are among $\mathrm{NE} 45^{\circ}$ and $\mathrm{NE} 90^{\circ}$ as well. Orientations of in-situ maximum horizontal principal stress by experiments fundamentally match the field monitored

\begin{tabular}{|c|c|c|c|c|c|c|c|c|c|}
\hline \multirow[b]{2}{*}{ Well NO. } & \multirow[b]{2}{*}{ Depth of cores(m) } & \multicolumn{2}{|c|}{$\sigma_{v}$} & \multicolumn{2}{|c|}{$\sigma_{H}$} & \multicolumn{2}{|c|}{$\sigma_{h}$} & \multirow[b]{2}{*}{$\sigma_{h}^{c o m}(\mathbf{M P a})$} & \multirow[b]{2}{*}{$\operatorname{Error}(\%)$} \\
\hline & & $\begin{array}{c}\text { Magni- } \\
\text { tude(MPa) }\end{array}$ & $\begin{array}{l}\text { Stress gra- } \\
\text { dient } \\
(\mathrm{MPa} / \mathrm{m})\end{array}$ & $\begin{array}{c}\text { Magni- } \\
\text { tude(MPa) }\end{array}$ & $\begin{array}{l}\text { Stress gra- } \\
\text { dient } \\
(\mathrm{MPa} / \mathrm{m})\end{array}$ & $\begin{array}{c}\text { Magni- } \\
\text { tude(MPa) }\end{array}$ & \begin{tabular}{|} 
Stress gradi- \\
ent \\
$(\mathrm{MPa} / \mathrm{m})$
\end{tabular} & & \\
\hline TPX1 & $6548.87-6549.03$ & 164.0 & 0.025 & 134.0 & 0.0205 & 105.0 & 0.0160 & 103.45 & 1.5 \\
\hline TPX3 & $6844.39-6844.54$ & 171.0 & 0.025 & 126.0 & 0.0184 & 95.0 & 0.0139 & 95.49 & 0.5 \\
\hline TPX4 & $6362.99-6363.14$ & 159.0 & 0.025 & 133.0 & 0.0209 & 100.0 & 0.0157 & 98.65 & 1.4 \\
\hline TPX5 & 6158.44-6158.55 & 157.0 & 0.025 & 129.0 & 0.0209 & 97.0 & 0.0158 & 98.6 & 1.6 \\
\hline TPX6 & $6274.38-6275.53$ & 154.0 & 0.025 & 126.0 & 0.0201 & 91.0 & 0.0145 & 92.08 & 1.2 \\
\hline TPX9 & $6211.21-6211.42$ & 155.0 & 0.025 & 129.0 & 0.0208 & 94.0 & 0.0151 & 95.6 & 1.7 \\
\hline \multicolumn{3}{|c|}{ Average stress gradient } & 0.025 & I & 0.0203 & I & 0.0152 & I & l \\
\hline
\end{tabular}
results.

Table 5. Stress of the Carbonate Reservoir in Tahe Oilfield by The Improved DSA 


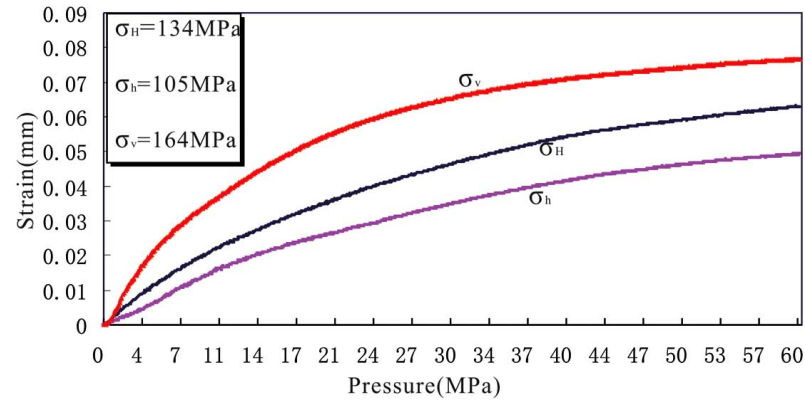

a. TPX1 wel

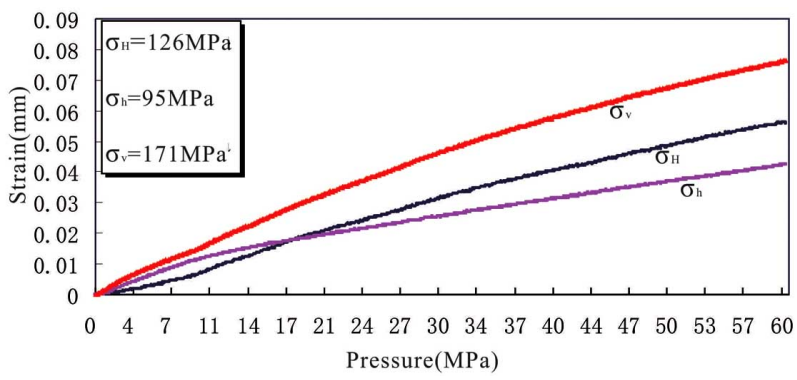

c. TPX3 well

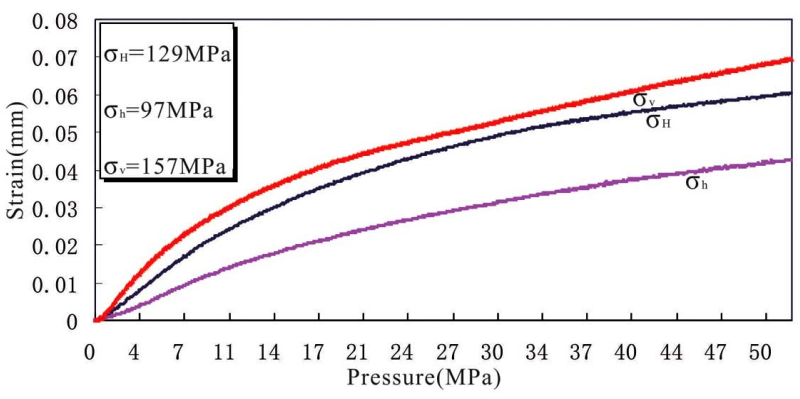

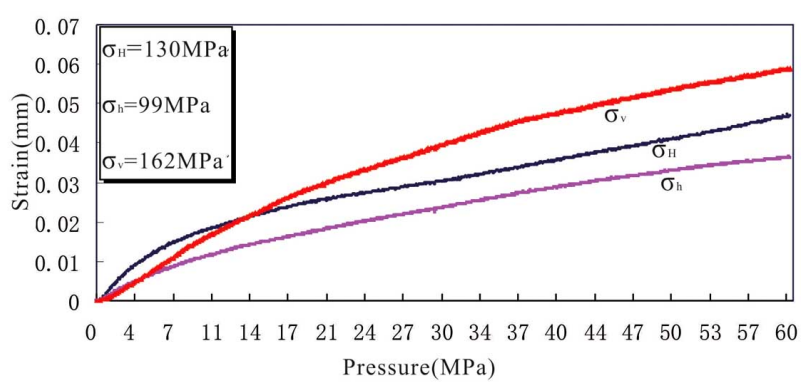

b. TPX2 well

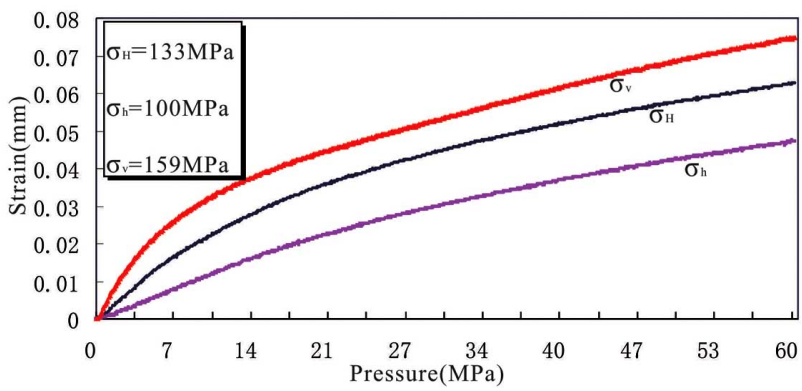

d. TPX4 well

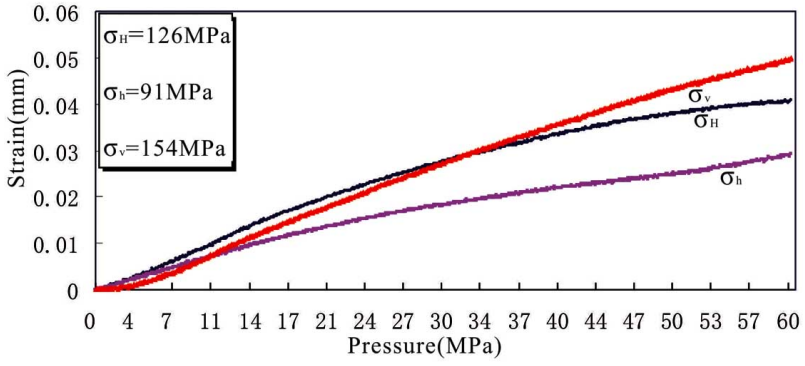

e. TPX5 well f. TPX6 well

Fig. (5). Strain curves of three principal stress of TPX1 well to TPX6 well.

\subsection{Comparison of Magnitude of In-situ Minimum Horizontal Principal Stress}

In-situ minimum horizontal stress can be obtained from fracturing, which is a direct method. The magnitude of insitu minimum horizontal stress with this method is the most accurate, so this method is widely applied. According to the acid fracturing operation curve, a pressure decline curve at the well head can be obtained when stopping the pump more than half an hour during the process of acid fracturing. Insitu minimum horizontal principal stress can be predicated by the pressure decline curve and the depth of the reservoir. The acid fracturing operation curve of TPX3 is shown in Fig. (6). The depth of the reservoir is between $6784.04 \mathrm{~m}$ and $6881.0 \mathrm{~m}$. Accordingly, the magnitude of minimum horizontal principal stress is about $95.49 \mathrm{MPa}$, while the magnitude of minimum horizontal principal stress is
$95.13 \mathrm{MPa}$ at the depth of $6844.39 \mathrm{~m}$ to $6844.54 \mathrm{~m}$ by laboratory tests. The very small difference of stress predicted by the two methods shows that the improved DSA method is reliable and practical.

All the minimum horizontal principal stress obtained from acid fracturing operation curves are shown in Table 5. A good match between experimental results and field monitored results show that the improved Differential Strain Analysis (DSA) method is reliable and practical.

\section{CONCLUSIONS}

In this paper, we designed an improved differential stain analysis for in-situ stress measurement for small full diameter cores from deep or super deep wells. With the improved method, we combine wave velocity anisotropy method and palaeomagnetic core reorientation method to 


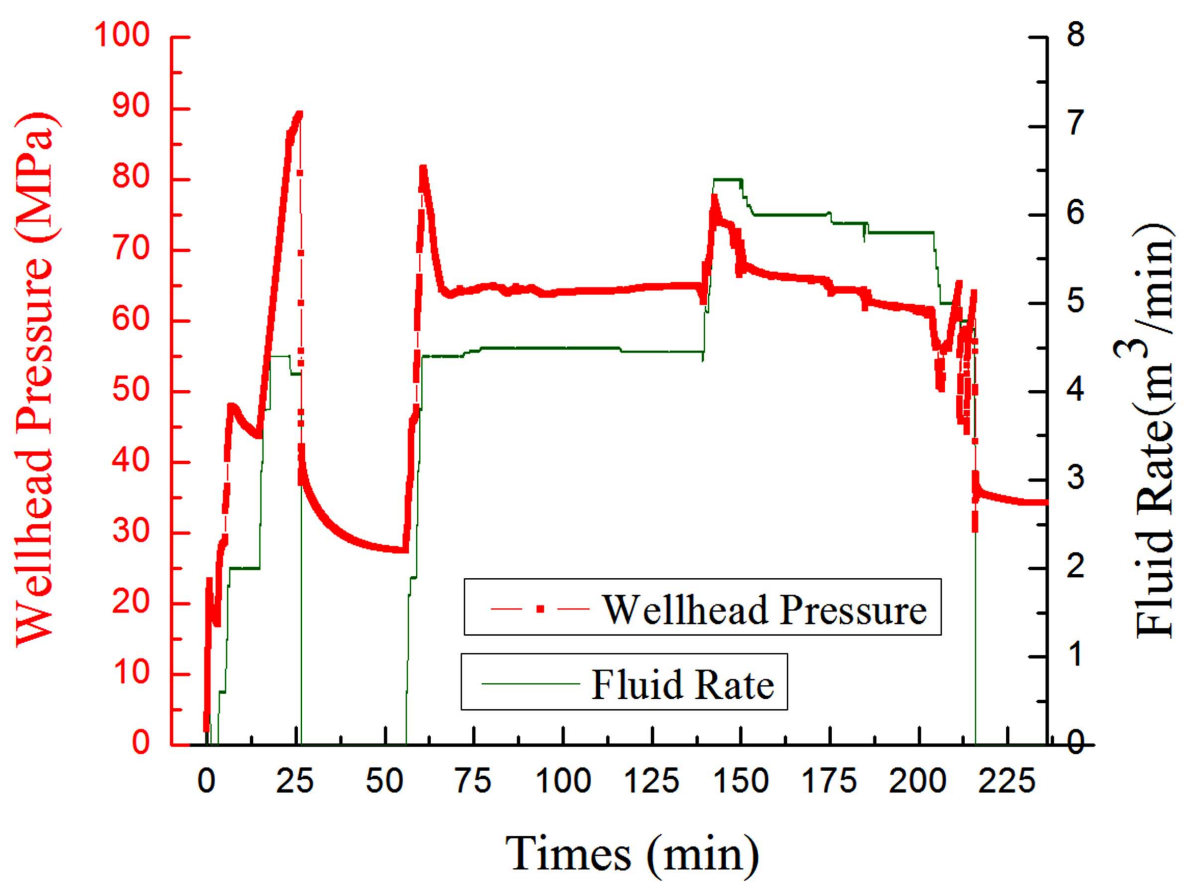

Fig. (6). Acid fracturing operation curve on TPX3 well in the carbonate reservoir.

develop a suit of improved experimental program on in-situ stress measurement with small diameter cylindrical cores.

Using the improved experimental program, we measured magnitude and orientation of in-situ stress of the carbonate reservoir in Tahe Oilfield. The results show that the orientation of maximum horizontal principle stress mainly distributes among $\mathrm{NE} 45^{\circ}-90^{\circ}$, the gradient of vertical principle stress is $0.025 \mathrm{MPa} / \mathrm{m}$, the gradient of horizontal maximum principle stress is $0.0203 \mathrm{MPa} / \mathrm{m}$, and the gradient of minimum horizontal principle stress is $0.0152 \mathrm{MPa} / \mathrm{m}$.

The good match between experimental results and fieldmonitored results shows that the improved experimental program is reliable and practical.

\section{LIST OF SYMBOLS}

$$
\begin{aligned}
& \sigma_{v} \quad=\text { In-situ vertical principal stress, } \mathrm{Pa} \\
& \sigma_{H} \quad=\text { In-situ horizontal maximum principal } \\
& \text { stress, } \mathrm{Pa} \\
& \sigma_{h} \quad=\text { In-situ horizontal minimum principal } \\
& \text { stress, } \mathrm{Pa} \\
& \varepsilon_{v} \quad=\text { Principal strain of vertical direction, } \\
& \text { dimensionless } \\
& \varepsilon_{H} \quad=\text { Principal strain of horizontal maximum } \\
& \text { principal stress direction, dimensionless } \\
& \varepsilon_{h} \quad=\text { Principal strain of horizontal minimum } \\
& \text { principal stress direction, dimensionless } \\
& \mu \quad=\text { Poisson's ratio of rock, dimensionless } \\
& \sigma_{h}^{\text {com }} \quad=\text { In-situ horizontal minimum principal stress } \\
& \text { computed from acid fracture operation } \\
& \text { curve, } \mathrm{Pa}
\end{aligned}
$$

$\theta$

$\begin{aligned}= & \text { Orientation of maximum horizontal } \\ & \text { principal in-situ stress, }{ }^{\circ}\end{aligned}$

\section{CONFLICT OF INTEREST}

The authors confirm that this article content has no conflicts of interest.

\section{ACKNOWLEDGEMENTS}

The study was subsidized by National Science and Technology Major Project foundation.

\section{REFERENCES}

[1] Z. M. Li, and J. Z. Zhang, In-Situ Stress and Petroleum Exploration \& Development, Petroleum Industry Press: Beijing, 1997.

[2] P. C. Dong, "Orientation determination of maximum horizontal stress in reservoir formation by paleomagnetic orientation of cores", Chinese Journal of Rock Mechanics and Engineering, vol. 23, no.14, pp. 2480-2483, 2004.

[3] B. J. Pestman, and J. G. Van Munster, "Acoustic emission study of damage development and stress-memory effects in sandstone", International Journal of Rock Mechanics and Mining Sciences \& Geomechanics Abstracts, vol. 33, no. 6, pp. 585-593, 1996.

[4] A. Lehtonen, S. Mononen, and J. Antikainen, "Laboratory testing methods for in-situ stress measurement and time-to-failure prediction", In: 11th Congress of the International Society for Rock Mechanics, L. R. Sousa, C. Olalla, N. Grossmann, Eds., 2007, pp. 335-338.

[5] Y. D. Xue, and D. L. Gao, "Determination of Kaiser point in measurement of geo-stress with acoustic emission", Journal of the University of Petroleum, China, vol. 24, no. 5, pp.1-4, 2000.

[6] F. G. Strickland, and R. Nae-Kan, "Use of Differential Strain Curve Analysis in predicting in-situ stress state for deep wells", In: the 21st U.S. Symposium on Rock Mechanics (USRMS), 1980, pp. 251-260.

[7] P. J. Perreau, O. Heugas, and F. J. Santarelli, "Tests of ASR, DSCA, and Core discing analyses to evaluate In-Situ Stresses", In Middle East Oil Show, 1989, pp. 1-13.

[8] H. C. Shen, Y. F. Cheng, J. Y. Wang, Y. Z. Zhao, and J. G. Zhang, "Principal direction differential strain method for in-situ stress measurement and application", XinJiang Petroleum Geology, vol. 29, no. 2, pp.250-252, 2008. 
[9] Y. F. Cheng, H. C. Shen, and Y. D. Zhao, "A simplified differential strain analysis stress method for in-situ stress measurement", Oil

(C) Pan et al.; Licensee Bentham Open.

This is an open access article licensed under the terms of the Creative Commons Attribution Non-Commercial License (http://creativecommons.org/licenses/by-nc/3.0/) which permits unrestricted, non-commercial use, distribution and reproduction in any medium, provided the work is properly cited. 